\title{
Kitosan/к-Karragenan/Kitosan Üç Tabakalı Mikrokürelerinden İndometazinin Kontrollü Salımı
}

\author{
Murat İNAL ${ }^{1^{*}}$ \\ ${ }^{1}$ Biyomühendislik Bölümü, Mühendislik Fakültesi, Kırıkkale Üniversitesi, Kırıkkale, Türkiye \\ 1*inalmrt@yahoo.com, minal@kku.edu.tr
}

(Geliş/Received: 27/11/2019;

Kabul/Accepted: 29/05/2020)

Öz: Bu çalı̧̧mada, modifiye edilmemiş kitosan mikrokürelerinin $\mathrm{pH}$ dayanıklılığını arttırmak için $\kappa$-karragenan ve kitosan ile kaplanmış kitosan mikroküreleri sentezlenmiştir. Çalışmanın çıkış noktası tripolifosfat ile çapraz bağlanmış kitosan ve $\kappa-$ karragenan kaplanmış kitosan mikrokürelerinin $\mathrm{pH}$ 1,2 $\mathrm{HCl}-\mathrm{KCl}$ tamponu içerisinde 30 dakika içinde parçalanmalarıdır. Bunu önlemek ve yeni bir kontrollü salım sistemi geliştirmek için kitosan/א-karragenan/kitosan üç tabakalı mikroküreleri sentezlenmiştir. Model ilaç olarak indometazin (IM) kullanılmıştır. Mikrokürelerin yüzey yapısı taramalı elektron mikroskobu (SEM) ile incelenmiştir. Mikrokürelerdeki $\kappa$-karragenanın ve ilacın varlığı, Fourier dönüşümlü kızılötesi spektroskopisi (FTIR) kullanılarak tespit edilmiştir. Mikrokürelerin içine hapsedildikten sonra ilacın kimyasal dayanıklılığı diferansiyel taramalı kalorimetre (DSC) ile belirlenmiştir. Hazırlanan mikroküreler ilaç hapsetme etkinliği, denge şişme derecesi, parçacık boyutu ve kontrollü salım verileri ile karakterize edilmiștir. Kontrollü salım çalışmaları pH 1,2 HCl-KCl tamponu ve peşinden pH 7,4 fosfat tamponu içerisinde gerçekleştirilmiştir. IM salımı üzerine çapraz bağlayıcı derişimi ve kitosan/ilaç oranının etkileri incelenmiștir. Mikrokürelerde $\kappa$-karragenanın ve IM varlığı FTIR analizi ile doğrulanmıștır. İlacın mikrokürelere hapsedildikten sonra yapısını koruduğu DSC ölçümleri ile kanıtlanmıştır. Çapraz bağlayıcı derişiminin ve ilaç miktarının artması ile kürelerden ilaç salımının azaldığı bulunmuştur. Yeni elde edilen sistemin özellikle midede tahrişe sebep olan ilaçlar için uygun bir kontrollü salım sistemi olduğu belirlenmiştir.

Anahtar kelimeler: Kitosan, $\kappa-$ karragenan, indometazin, mikroküre, kontrollü salım sistemi.

\section{Controlled Release of Indomethacin from Chitosan / א-Carrageenan / Chitosan Three Layer Microspheres}

\begin{abstract}
In this study, $\kappa$-carrageenan and chitosan coated chitosan microspheres were synthesized to increase the $\mathrm{pH}$ resistance of unmodified chitosan microspheres. The starting point of the study was the disintegration of chitosan and $\kappa-$ carrageenan coated chitosan microspheres cross-linked with tripolyphosphate in $\mathrm{pH} 1.2 \mathrm{HCl}-\mathrm{KCl}$ buffer within 30 minutes. Three-layer microspheres of chitosan/ $\kappa$-carrageenan/chitosan were synthesized to prevent this condition and develop a new controlled release system. Indomethacin (IM) was used as a model drug. The surface structure of the microspheres was examined by scanning electron microscopy (SEM). The presence of carrageenan and drug in the microspheres was determined using Fourier transform infrared spectroscopy (FTIR). After being entrapped into the microspheres, the chemical resistance of the drug was determined by differential scanning calorimetry (DSC) measurements. The prepared microspheres were characterized by drug entrapment efficiency, degree of equilibrium swelling, particle size, and controlled release data. Controlled release studies were carried out in $\mathrm{pH} 1.2 \mathrm{HCl}-\mathrm{KCl}$ buffer followed by $\mathrm{pH} 7.4$ phosphate buffer. The effects of crosslinker concentration and chitosan/drug ratio on IM release were investigated. The presence of $\kappa$-carrageenan and IM in the microspheres was confirmed by FTIR analysis. With DSC measurements, the drug has been proven to retain its structure after capturing microspheres. It was found that as the crosslinker concentration and drug amount increased, drug release from the spheres decreased. It has been determined that the newly obtained system is a controlled release system suitable for drugs that cause irritation especially in the stomach.
\end{abstract}

Key words: Chitosan, $\kappa$-carrageenan, indomethacin, microsphere, controlled release system.

\section{Giriş}

Alışılmış dozaj şekillerinde kandaki ilaç seviyesi bir süre artmakta, sonra istenilen plazma düzeyine ulaşarak kısa bir süre sabit kalarak, hızla azalmaktadır. Klasik ilaç şekillerinin kullanımında görülen bu tür aksaklıkların giderilmesine yönelik yapılan araştırmalara en iyi yanıt veren sistemler kontrollü ilaç salım sistemleridir. Organizma için gerekli olan etkin maddenin salım hızını kontrol ederek hedef hücreye, dokuya veya organa ulaştıran sistemlere kontrollü salım sistemleri adı verilir. Kontrollü salım sistemleri, ilaçların dozunun

\footnotetext{
* Sorumlu yazar: inalmrt@yahoo.com.tr. Yazarların ORCID Numaras1: ${ }^{10000-0003-3384-5627 ~}$
} 
azaltılabilmesi, alımının daha uzun aralıklara yayılabilmesi, yan ve zararlı etkilerinden arındırabilmesi ve hedef bölgeye gönderilebilmesi gibi üstünlükleri dolayısıyla son yıllarda klasik ilaç kullanım yöntemlerinin yerini almaktadır. Kontrollü salım sistemlerinde belirli bir doz alındıktan sonra etkin madde plazma düzeyi istenilen süre (10-12 saat, bir gün, bir hafta veya bir yıl) sabit kalır ve böylece hasta sık sık ilaç almaktan kurtularak, plazmanın etkin madde düzeyi değişmediği için başarılı bir tedavi oldukça düşük doz ile sağlanabilir [1].

Kitin doğada selülozdan sonra ikinci en çok bulunan polisakkarittir ve ticari olarak 1stakoz, karides ve yengeçlerin atık kabuklarından elde edilmektedir [2-4]. Kitosan (KTS), kitinin bazik ortamda asetil grubunun yapıdan uzaklaştırılması ile elde edilmektedir. KTS N-asetil-D-glikoz amin ve D-glikoz aminin $\beta-1,4$ glikozit bağları ile bağlanmasıyla oluşan bir kopolimerdir. [2,4-6]. KTS serbest amino grupları içerdiği için nötral ve bazik pH'larda nötr bir polisakkarittir ve bu yüzden suda çözünmez. Fakat asidik pH'larda amino grupları protonlandığı için suda çözünmektedir. Çözünürlüğü serbest amino ve N-asetil gruplarının dağılımına bağlıdır [7]. Genellikle \%1-3 asetik asit içerisinde çözünmektedir. KTS alerjik reaksiyonlara ve vücutta reddedilmeye yol açmadığ için yaşayan dokular ile biyouyumludur. Amino şekerleri vücutta yavaş yavaş zararsız ürünlere parçalandığı için insan vücudu tarafından tamamen emilir ve vücutta bölgesel yan etkilere sebep olmadan organizmadan kolayca atılabilir. Ayrıca bunlara ek olarak iyi antimikrobiyal, adezyon ve koagülasyon özelliklerine de sahiptir [8]. KTS'nin birincil amin gruplarının bulunması onu eczacılık uygulamalarında çok kullanışı bir hale getirmektedir. Birçok doğal polimerler ile karşılaş̧ırıldığında KTS pozitif yüklü ve mukozaya yapışabilen bir yapıya sahiptir. Bu yüzden, ilaç salım sistemlerinde yaygın olarak kullanılmaktadır [9-11]. İlacın salımı, çok değerli anyonlarla (sülfat, sitrat veya tripolifosfat) KTS'nin iyonik çapraz bağlanması sayesinde veya anyonik polimerlerle (poliakrilatlar, hyalüronik asit, aljinat, pektin veya karragenan) dayanıklı kompleksler oluşturularak kontrol edilebilmektedir.

Karragenan (KRG), Chondrus, Eucheuma, Gigartina, and Hypnea gibi kırmızı deniz yosunlarının belirli türlerinin ekstraksiyonu ile elde edilen yüksek molekül ağırlıklı sülfat grubu içeren polisakkaritlerin bir ailesi için genel bir isimdir. $\mathrm{Bu}$, glikozidik bağlar ile bağlanmış galaktoz ve anhidrogalaktoz birimlerinden oluşmaktadır. Gıda endüstrisinde, KRG yaygın olarak jelleştirici, kıvam artııııı, emülsifiye edici ve dengeleyici olması gibi mükemmel fiziksel fonksiyonel özelliklerini nedeniyle kullanılmaktadır. [12-14]. Bunlar esas olarak dönüşümlü olarak bağlanmış 3-bağl1- $\beta$-D-galaktopiranoz ve 4-bağl1- $\alpha$-D-galaktopiranoz birimlerinden oluşmaktadır ve bunlar serbest hidroksil gruplarının sübstitüsyon derecesine göre sınıflara ayrılmaktadır. Sübstitüsyon genellikle sülfat esterinin bağlanması ya da 4-bağlı artıkların 3,6 birimlerinin anhidrid olușturması ile gerçekleșmektedir $[14,15]$. Bu polisakkaritler geleneksel olarak 6 temel formdan oluşmaktadır; Kappa $(\kappa)-$, Iota $(\tau)-$, Lambda $(\lambda)-$, $\mathrm{Mu}(\mu)-, \mathrm{Nu}(v)-$ ve Theta $(\theta)-K R G$. Bu adlandırma, kimyasal yapıları ve ticari üretimleri ile alakalıdır, çünkü farklı KRG alt tipleri farklı yosun kaynaklarından elde edilmektedir. KRG çeşitlerinin özelliklerini etkileyen temel farklılıklar ester sülfat gruplarının konumu ve sayısı ve 3,6-anhidro-galaktoz içeriğidir. Örneğin, ester sülfat içeriği yüksek seviyelerde olduğunda düşük çözünürlük sıcaklığı ve düşük jel kuvveti ile sonuçlandığı bildirilmiștir $[14,16]$. Özellikle sülfat gruplarından dolayı anyonik bir polimer olan $\kappa-K R G$ katyonik polimerlerle (KTS v.b...) etkileşerek son yıllarda ilaç formülasyonlarının hazırlanmasında ve özellikle doku iskelelerinin oluşturulmasında kullanımı artmıștır. Tapia ve ark. [17] KTS-aljinat ve KTS-KRG kompleks polimerleri hazırlamışlardır. Hazırlanan kompleks polimerler FTIR ve şişme davranışları ile karakterize edilmişlerdir. Ayrıca kompleks polimerlerle diltiazem hidroklorür içeren tabletler oluşturularak, bu tabletlerin çözünme testlerini gerçekleştirmişlerdir. Long ve ark. [18] $\mathrm{KTS}-\mathrm{KRG}-\mathrm{Fe}_{3} \mathrm{O}_{4}$ nanopartiküllerini sentezlemişlerdir. Daha sonra bunların içine sığır serum albümini adsorbe ederek nanopartiküllerden proteinin salım davranışlarını incelemişlerdir.

İndometazin (IM) ateş düşürücü, ağrı kesici özelliklerinden dolayı kullanılan steroid yapıda olmayan, iltihabi reaksiyonu önleyici bir ilaçtır. IM genellikle oral yoldan kullanılır. Sindirim kanalında hızla emilir ve maksimum kan plazma düzeyine 2 saatte ulaşır. IM diğer iltihabi reaksiyonu önleyici ilaçlar gibi mide mukozası ile uzun süreli teması halinde insanlarda kullanımından sonra gastrointestinal kanalda bölgesel tahrişlere, kanamalara hatta peptik ülsere sebep olmaktadır ve bu gibi etkileri uzun süreli kullanımını sınırlamaktadır [19,20]. IM gastrointestinal sistemdeki çözünürlüğü çok düşük olduğu için düşük oral biyoyararlanım gösterir, ayrıca suda hemen hemen pratik olarak hiç çözünmez $(0,02 \mathrm{mg} / \mathrm{mL})$ [21].

$\mathrm{Bu}$ çalışmanın amacı, IM'nin yukarıda sayılan zararlarını ve ilacın kan seviyesinde görülen dalgalanmaları önleyebilmek için bir kontrollü salım sistemi geliştirebilmektir. Bu amaçla ilk olarak IM, KTS içine sodyum tripolifosfat (TPP) çapraz bağlayıcısı yardımıyla hapsedilmiştir. Daha sonra hazırlanan mikroküreler salım hızını azaltmak ve salım zamanını kontrol altına alabilmek amacıyla ilk olarak $\kappa-K R G$ çözeltisine aktarılarak yüzeyinin bu polimerle kaplanması sağlanmıştır. Bu aşamada kitosan üzerindeki pozitif yüklü amino grupları ile $\kappa-\mathrm{KRG}$ üzerindeki negatif yüklü sülfonat grupları etkileșerek $\kappa-K R$ G'nin mikrokürelerin yüzeyine tutunması sağlanmıştır. Tutunan polimer potasyum klorür ile çapraz bağlanarak yapıdan ayrılmaması sağlanmıştır. Benzer şekilde $\kappa-K R G$ 
ile kaplanan küreler bu sefer KTS çözeltisine aktarılarak yüzeyinin bu polimerle kaplanması sağlanmıştır. Daha sonra KTS, TPP yardımıyla çapraz bağlanarak yüzeyden uzaklaşması engellenmiştir. Yine bu kaplama işlemi de ilacın salım hızını azaltacağı ve salım zamanını kontrol altına alacağı için yapılmıştır. Mikrokürelerin yüzeyi anlatıldığı şekilde modifiye edilerek tek başına KTS'nin kullanıldı̆̆ 1 sistemlere oranla özellikle asidik şartlara karşı son derece dayanıklı ve çok daha uzun süreli salım sağlayan bir kontrollü ilaç salım sistemi geliştirilmiş olacaktır.

\section{Materyal ve Metot}

\subsection{Kullanılan kimyasal maddeler}

KTS (orta viskozitede) Sigma-Aldrich (İzlanda) ve dipotasyum monohidrojen fosfat Merck (Almanya) firmalarından temin edilmiştir. İndometazin, $\kappa-K R G$, hidroklorik asit, sodyum hidroksit, sodyum tripolifosfat ve potasyum klorür Sigma-Aldrich (Amerika) firmasından temin edilmiştir. Bütün kimyasallar alındığı şekliyle kullanılmıştır.

\subsection{IM yüklü kitosan mikrokürelerinin hazırlanmas}

$\% 0,5(\mathrm{~h} / \mathrm{h})$ asetik asit çözeltisi içerisinde kütlece \%2 (k/h) olacak şekilde KTS çözülmüştür. Sonra bundan $20 \mathrm{~mL}$ alınarak içerisine KTS'ye oranla \%20,40 ve 60 (k/k) olacak şekilde IM ilave edilmiştir. Sonra polimer-ilaç çözeltisi iğne ucu ile $(0,9 \mathrm{~mm}$ et kalınlığı olan) $1000 \mu \mathrm{L} /$ dakika akış hızında şırınga pompası ile (New Era EN300, Amerika) TPP içeren sulu çözelti içerisine damlatılmıştır. Oluşan küreler 15 dakika olgunlaştırılmıştır. Oluşan küreler KRG ile kaplanması amacıyla distile su ile bir kere yıkanıp KRG çözeltisi içeresine aktarılmıştır. Burada 15 dakika karıştırıldıktan sonra yine su ile bir kez yıkanıp bu sefer KRG'yi çapraz bağlamak amacıyla potasyum klorür $(\mathrm{KCl})$ çözeltisi içine aktarılmıştır. 15 dakikada burada çapraz bağlanma gerçekleştirilmiştir. Daha sonra KRG kaplı küreler üzerine KTS kaplamak amacıyla KTS çözeltisi içerisine ilave edilmiştir. Burada 15 dakika karıştırıldıktan sonra küreler alınarak yine su ile bir kez yıkanıp bu sefer TPP'nin sulu çözeltisi içerisine aktarılmıştır. Yine burada 15 dakika olgunlaştırılan küreler yıkanmıştır. Boş kürelerde aynı şekilde elde edilmiştir. Daha sonra küreler $35^{\circ} \mathrm{C}$ 'de etüvde (Nüve FN-120, Türkiye) kurutulmuştur. Her bir formülasyona ait olan sabit tartıma gelmiş ilaç yüklü ve kuru kürelerden 10'ar tane örnek alınarak dijital mikrometre (Mitutoyo IP.65, Japonya) ile kürelerin ortalama çapları belirlenmiştir. Kürelerin formülasyonları Tablo1'de verilmiştir.

Tablo 1. Boş ve ilaç yüklü mikrokürelerin hazırlanma koşulları

\begin{tabular}{|c|c|c|c|c|c|c|}
\hline Küre No & TPP $(\mathbf{M})$ & IM (\%k/k) & KRG (\%k/h) & KCl $(\mathbf{M})$ & KTS (\%k/h) & TPP $(\mathbf{M})$ \\
\hline 1 & 0,012 & 20 & 0,2 & 0,5 & 0,5 & 0,012 \\
\hline 2 & 0,024 & 20 & 0,2 & 0,5 & 0,5 & 0,024 \\
\hline 3 & 0,036 & 20 & 0,2 & 0,5 & 0,5 & 0,036 \\
\hline 4 & 0,024 & 40 & 0,2 & 0,5 & 0,5 & 0,024 \\
\hline 5 & 0,024 & 60 & 0,2 & 0,5 & 0,5 & 0,024 \\
\hline 6 & 0,012 & - & 0,2 & 0,5 & 0,5 & 0,012 \\
\hline 7 & 0,024 & - & 0,2 & 0,5 & 0,5 & 0,024 \\
\hline 8 & 0,036 & - & 0,2 & 0,5 & 0,5 & 0,036 \\
\hline
\end{tabular}

\subsection{IM yüklü mikrokürelerin tutuklama verimi (\%TV)}

Kürelerdeki ilaç miktarının belirlenmesi için yapılan bir işlemdir. İlacın kürelere gerçekte ne kadar yüklendiğinin bir ölçüsüdür. Tutuklanma verimi hesabı için IM yüklü kürelerden $20 \mathrm{mg}$ alınarak havanda toz haline gelene kadar ezilmiştir, elde edilen toz hacimce \%30-70 (h/h) olacak şekilde etanol-pH 7,4 fosfat tamponu ile bir balona alınmıştır ve geri soğutucu altında bir manyetik karıştırıcı yardımıyla ilacın ekstrakte olması sağlanmıştır. Daha sonra çözelti süzülmüş ve IM içeriği UV spektrofotometresi (Biochrom Libra S-70, İngiltere) ile 262 nm'de belirlenmiştir. Tutuklanma yüzdesi Denklem 1'e göre hesaplanmıştır.

$\% \mathrm{TV}=\frac{\text { Küre içindeki deneysel IM miktarı }}{\text { Küre içindeki teorik IM miktarı }} \times 100$ 


\subsection{IM yüklü mikrokürelerin hücre dışı salım çalış̧maları}

Hücre dışı ilaç salım çalışması için belirli miktarda küre alınmış ve küreler pH 1,2 $\mathrm{HCl}-\mathrm{KCl}$ tamponu çözeltisi içeren balona ilave edilmiş ve $37^{\circ} \mathrm{C}$ ve 100 devir/dakika çalkalama hızındaki su banyosuna (JeioTech BS-21, Kore) yerleştirilmiştir. IM salımı, 2 saat süre ile $\mathrm{pH}$ 1,2 HCl-KCl tamponu çözeltisinde, daha sonra bu çözeltiden alınarak pH 7,4 fosfat tamponunda gerçekleştirilmiştir. Her 30 dakikada balonlardan örnekler alınarak, UV spektrofotometresin de kürelerden salınan IM miktarı $262 \mathrm{~nm}$ 'de dalga boyunda belirlenmiştir. Balonlara, salım ortamına göre, alınan örnek hacmi kadar yeni hazırlanmıs $\mathrm{HCl}-\mathrm{KCl}$ veya fosfat tamponu çözeltileri eklenmiştir.

\subsection{Mikrokürelerin denge su içeriklerinin tayini}

Boş kürelerin şişme yeteneklerini belirlemek amacıyla belirli miktarda küre alınmıştır. Küreler pH 1,2 HCl$\mathrm{KCl}$ tamponu ve $\mathrm{pH} 7,4$ fosfat tamponu çözeltilerinin içinde 24 saat süre ile şişme dengesine gelene kadar $25^{\circ} \mathrm{C}$ 'de bekletilmiştir. Bu sürenin sonunda kürelerin yüzeyindeki çözelti kalıntıları uzaklaş̧ırılarak şişen küreler tartılmış ve kürelerin şişme derecesi Denklem 2 kullanılarak belirlenmiş̧ir.

\%Denge şişme derecesi $=\frac{\text { Şişmiş küre kütlesi }- \text { kuru küre kütlesi }}{\text { kuru küre kütlesi }} \times 100$

\section{Bulgular ve Tartışma}

\subsection{IM yüklü mikrokürelerin karakterizasyonu}

IM yüklü kürelerin tutuklanma verimi (\%TV) ve çapları Tablo 2'de verilmiştir.

Tablo 2. IM yüklü mikrokürelerin tutuklanma verimi (\%TV) ve çapları

\begin{tabular}{|c|c|c|}
\hline Küre No & Tutuklanma Verimi $(\boldsymbol{\%})$ & Küre çapları $(\boldsymbol{\mu m})$ \\
\hline 1 & 65,57 & 710,91 \\
\hline 2 & 73,46 & 698,25 \\
\hline 3 & 69,36 & 681,27 \\
\hline 4 & 79,18 & 912,80 \\
\hline 5 & 84,16 & 1015,30 \\
\hline
\end{tabular}

Tablo 2 incelendiğinde mikrokürelerin tutuklanma verimlerinin oldukça yüksek değerlere ulaştı̆̆ gözlemlenmiştir. Buda KTS mikrokürelerin kaplanmasının tutuklanma verimine oldukça olumlu bir etkisi olduğunu göstermektedir. Mikroküre çaplarına bakıldığında ise TPP derişiminin artması ile kürelerin çaplarının azaldığı, ilaç miktarının artması ile çaplarının arttığı gözlemlenmiş̦tir. TPP derişiminin artması ile kürelerin daha sağlam bir üç boyutlu ağ yapısı oluşturduğu, bunun da mikrokürelerin çaplarını azalttığı düşünülmüştür. Benzer sonuçlar Piyakulawat ve arkadaşlarının yaptığı çalışma da gösterilmiştir [22].

Sırasıyla boş ve ilaç yüklü mikrokürelerin FTIR ölçümleri (Bruker Vartex 70-V, Amerika) Şekil 1 ve Şekil 2'de gösterilmiştir. 


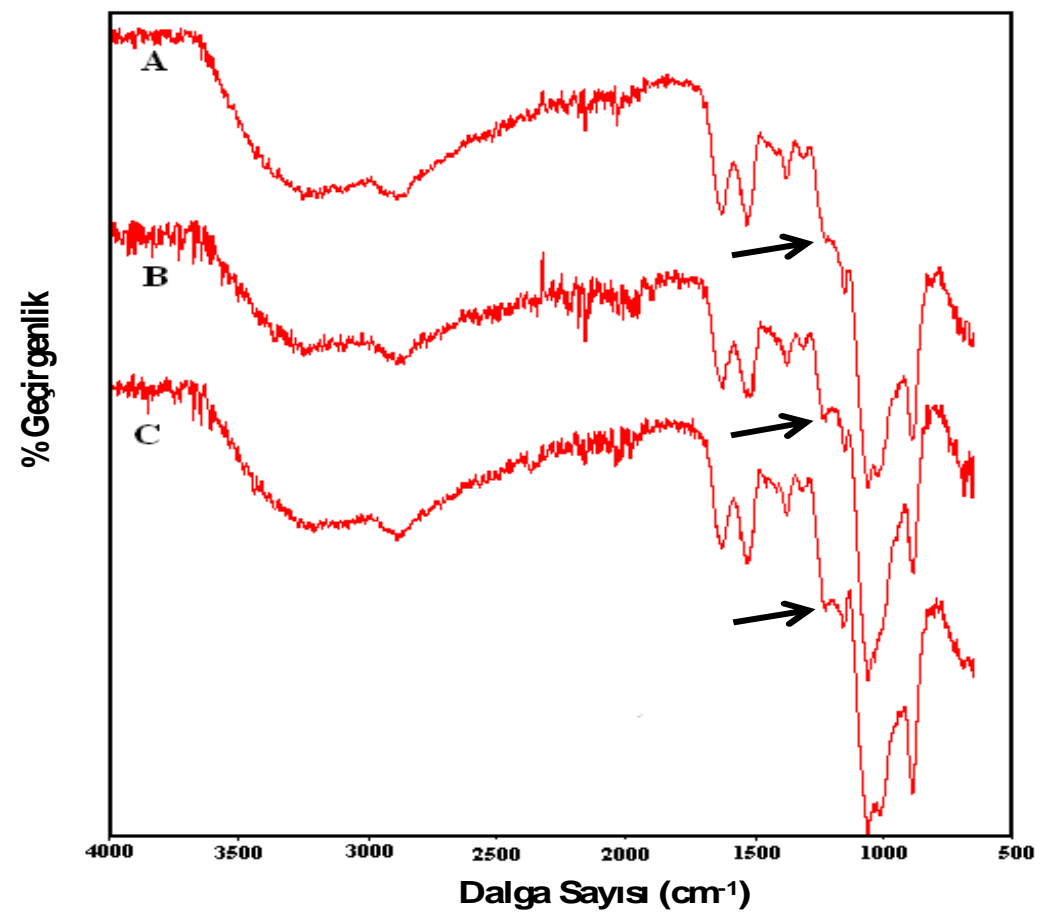

Şekil 1. Boş KTS (A), KRG kaplı KTS (B), KRG ve KTS kaplı KTS (C) mikrokürelerinin FTIR spektrumları

Şekil 1'de Boş KTS mikrokürelerinin spektrumu incelendiğinde 1630, 1550 ve $1380 \mathrm{~cm}^{-1}$ 'de sirasıyla amid 1, amid 2 ve C-N bağ 1 ile ilgili gerilme titreşimine ait bantlar görülmektedir. $1150 \mathrm{ve} 900 \mathrm{~cm}^{-1}$ 'de kitosanın polisakkarit yapısı ile ilgili karakteristik bantlar görülmektedir. Kaplanmış mikrokürelerin FTIR spektrumların da KRG tipik absorpsiyon bantları görülmektedir. Bu sonuç bize kitosan mikrokürelerinin KRG ile kaplandığını doğrulamaktadır. Bu bant, $1229 \mathrm{~cm}^{-1}$ 'de KRG'ın sülfonat grupların da bulunan S-O yapısı için asimetrik gerilme titreşimi olarak görülmektedir [23,24].

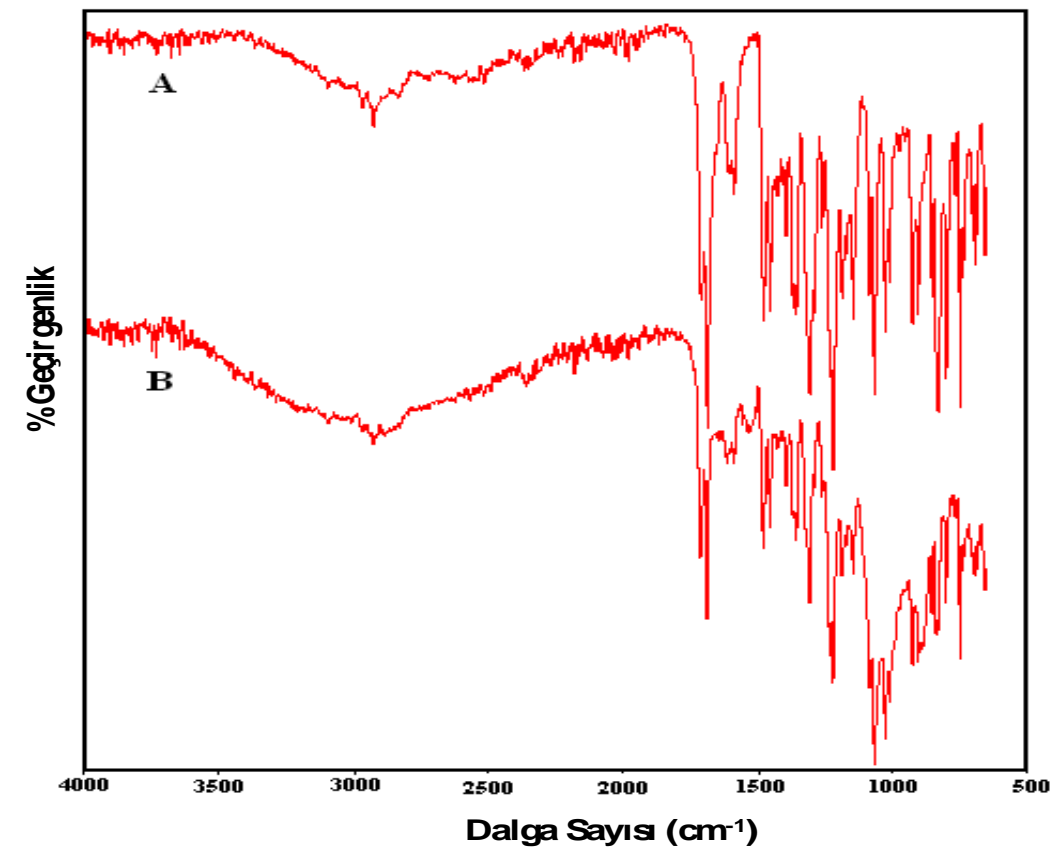

Şekil 2. IM (A) ve \%60 IM yüklü KRG ve KTS kaplı KTS mikrokürelerinin (B) FTIR spektrumları 
Şekil 2'de IM'nin spektrumunda $3000 \mathrm{~cm}^{-1}$ civarında gözlenen bandın molekülün benzen halkalarındaki aromatik $(\mathrm{C}-\mathrm{H})$ gerilmelerine, $2950 \mathrm{~cm}^{-1}$ civarındaki bantların alifatik $(\mathrm{C}-\mathrm{H})$ gerilmelerine, 1716 ve $1691 \mathrm{~cm}^{-1}$, de gözlenen bantların $(\mathrm{C}=\mathrm{O})$ gerilmelerine, 1591 ve $1480 \mathrm{~cm}^{-1}$ 'deki bantların aromatik $(\mathrm{C}=\mathrm{C})$ gerilmelerine, 1454 $\mathrm{cm}^{-1}$, deki bandın $\left(\mathrm{O}-\mathrm{CH}_{3}\right)$ gerilmesine, $1230 \mathrm{~cm}^{-1}$ deki bandın $(\mathrm{C}-\mathrm{O})$ gerilmelerine ve $752 \mathrm{~cm}^{-1}$ 'de gözlenen bandın $(\mathrm{C}-\mathrm{Cl})$ gerilmesine karşılık gelebileceği düşünülmüştür. IM yüklü kürelerin spektrumları incelendiğin de ilacın karakteristik bantlarını koruduğu gözlemlenmiştir. Buda bize ilacın polimerler ile hiçbir etkileşime girmeden yapısını koruduğunun bir kanıtıdır [25].

DSC analizi (TA Instrument Q-2000, Amerika) ilaç yüklü mikrokürelerin ve hapsedilen ilacın termal davranışını anlamak için yapılmıştır ve sonuçlar Şekil 3 'te gösterilmiştir.
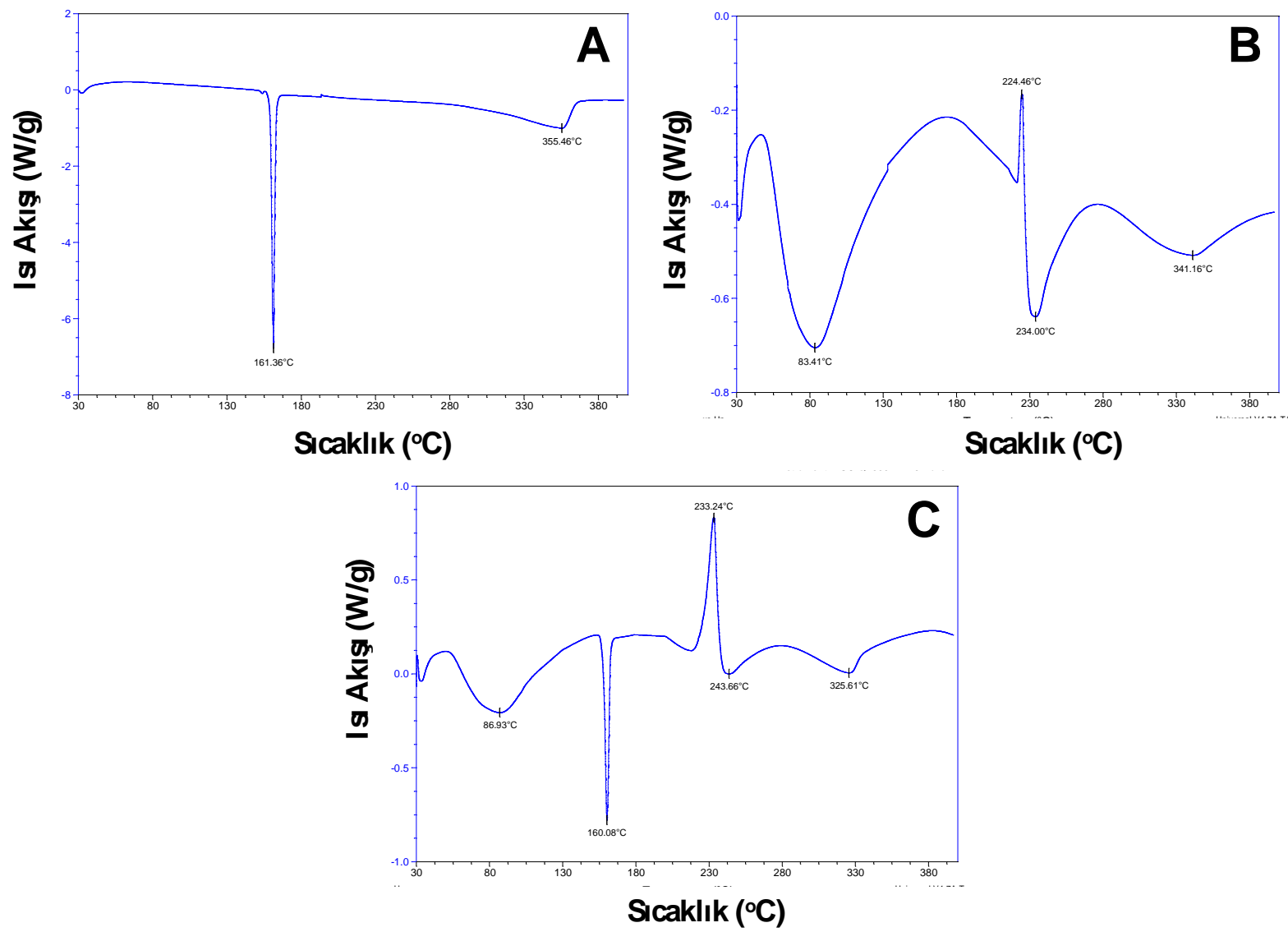

Şekil 3. IM (A), KRG ve KTS kaplı boş KTS (B) ve KRG ve KTS kaplı \%60 IM yüklü KTS mikrokürelerinin DSC termogramları

Boş ve ilaç yüklü mikroküreler yaklaşık 85 ve $230{ }^{\circ} \mathrm{C}$ 'de birbirine benzer $\mathrm{T}_{\mathrm{g}}$ ve parçalanma sicaklıkları göstermişlerdir. Aynı şekilde saf IM ve IM yüklü kürelerin termogramları incelendiğinde IM'nin erime noktası her iki termogramda da yaklaşı $160{ }^{\circ} \mathrm{C}$ olarak belirlenmiştir. Bu da bize ilacın polimerik matriks içinde kristal yapısını koruyarak dağıldı ğının bir kanıtıdır.

Boş ve ilaç yüklü mikrokürelerin SEM görüntüleri Şekil 4'te verilmiştir. Boş ve ilaç yüklü kürelerin son derece küresel şekilli oldukları açıkça gözlemlenmektedir. Boş KTS mikrokürelerin SEM sonuçları incelendiğinde kürelerin oldukça pürüzsüz bir yüzeye sahip oldukları görülmektedir. Küreler KRG ile kaplandığında yüzeylerinin oldukça pürüzlü bir hale geldiği görülmüştür. Bu sonuç bize $\mathrm{KRG}$ üzerindeki $-\mathrm{OSO}_{3}{ }^{-}$ grupları ile KTS üzerindeki $-\mathrm{NH}_{3}{ }^{+}$gruplarının elektrostatik etkileşim sergileyerek KRG moleküllerinin KTS mikrokürelerinin yüzeyine bağlandığının bir kanıtıdır. KRG kaplı mikroküreler tekrar KTS ile kaplandığında boş KTS mikrokürelerin de olduğu gibi yüzeyin yine pürüzsüz hale geldiği, fakat KRG'dan dolayı yine bir miktar yüzeyin girintili çıkıntılı halde olduğu görülmektedir. Elde edilen sonuçlar KTS mikrokürelerinin yüzeyinin KRG ve KTS ile kaplandığının oldukça sağlam kanıtlarını göstermektedir. 
İlaç yüklü mikrokürelerin SEM fotoğrafları incelendiğinde özellikle \%20 IM içeren kürelerin yüzeyindeki porlar açı bir şekilde gözlemlenmektedir. \%60 IM içeren mikroküre de ise ilaç moleküllerinin kristal halde yüzeye dağılmış olarak durduğu görülmektedir.

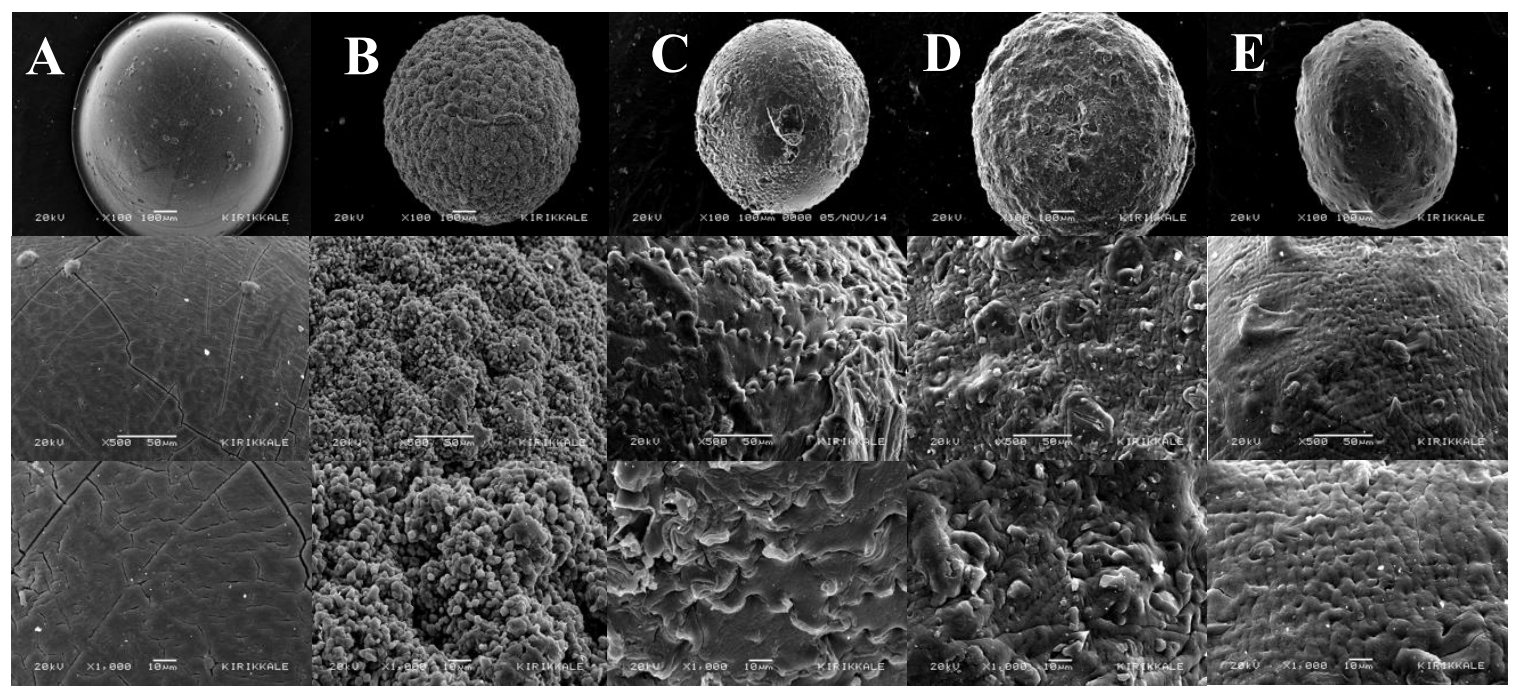

Şekil 4. Boş KTS(A), boş KRG kaplı KTS(B), boş KRG ve KTS kaplı KTS (C), \%60 IM yüklü (D) ve \%20 IM yüklü (E) KRG ve KTS kaplı KTS mikrokürelerinin SEM görüntüleri

\subsection{IM yüklü mikrokürelerden ilacın salım çalışmaları}

Mikrokürelerden IM salımına çapraz bağlayıcı TPP derişiminin ve mikrokürelerdeki IM içeriğinin etkisi incelenmiş ve sonuçlar Şekil 5.A ve 5.B'de gösterilmiştir.
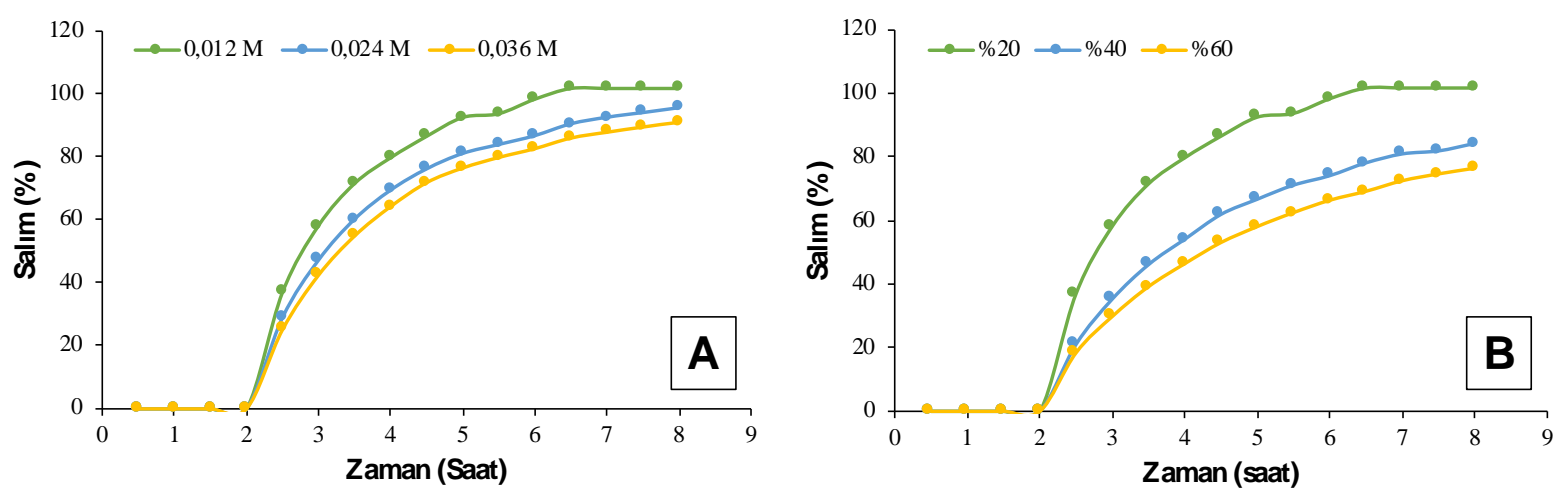

Şekil 5. KRG ve KTS kaplı KTS mikrokürelerinden IM salımı üzerine TPP derişiminin (A) ve ilaç yüzdesinin (B) etkisi

Şekil 5.A incelendiğinde TPP derişiminin artması ile kürelerden ilaç salımı azalmaktadır. Salımın azalmasının, TPP derişiminin artması ile mikrokürelerdeki çapraz bağ yoğunluğunun artmasına ve buna bağlı olarak polimerik matrisin daha rijit bir ağ yapısı meydana getirmesinden kaynaklandığı düşünülmektedir. Polimerik matriks daha sağlam bir ağ yapısı oluşturduğunda su moleküllerinin kürelerin içine difüzyonu azalmakta ve buna bağlı olarak ilaç moleküllerinin çözünerek kürelerden dışarı difüzyonu azalmaktadır. Benzer sonuçlar çeşitli çalışmalarda gösterilmiştir [26].

Şekil 5.B incelendiğin de mikroküreler içindeki ilaç yüzdesinin artması ile salım 8 saat sonun da \%100'den \%76'ya belirgin bir şekilde azalmıştır. Düşük ilaç yüzdesinde sıvı moleküllerinin kürelerin içine difüzyonu kolay 
olmaktadır ve buda kürelerden ilacın difüzyonunu hızlandırmaktadır. Benzer gözlemler de literatür de bulunmuştur [27].

\subsection{Hazırlanan boş mikrokürelerin denge şişme derecelerinin belirlenmesi}

Hazırlanan boş mikrokürelerin \% denge şişme dereceleri Tablo 3 ’te verilmiştir.

Tablo 3. Hazırlanan boș mikrokürelerin \% denge şişme dereceleri

\begin{tabular}{|c|c|c|}
\hline & HCl-KCl Tamponu & Fosfat Tamponu \\
\hline Küre No & \multicolumn{2}{|c|}{ \% Denge Şişme Derecesi } \\
\hline 6 & 1097,91 & 106,60 \\
\hline 7 & 1009,70 & 96,50 \\
\hline 8 & 922,32 & 92,54 \\
\hline
\end{tabular}

Boş kürelerin şişme davranışları incelendiğinde $\mathrm{pH}$ 1,2'de şişme derecelerinin 7,4'e göre oldukça yüksek olduğu görülmektedir. Bunun, düşük pH'da iyonlaşmış olan amino gruplarının birbirini itmesinden kaynaklandığ 1 düşünülmektedir. Bu sayede su molekülleri mikrokürelerin içine çok daha kolay difüzlenebilmektedir. pH'nın artması ile beraber amino gruplarının protonunu kaybetmesine bağlı olarak su moleküllerinin kürelerin içine difüzyonu zorlaşmaktadır [28].

Boş kürelerin fosfat tamponundaki şişme değerleri salım verileri ile uyumluluk göstermektedir. Çapraz bağlayıcı derişiminin artması ile şişme değerleri azalmaktadır. Bunun çapraz bağlayıcı derişiminin artmasıyla polimerik malzemede ki çapraz bağ yoğunluğunun artmasına, çapraz bağlanmanın artmasıla da polimerin hareketliliğinin azalmasına ve kürelerin yüzeyindeki porların daralmasına bağlı olarak suyun kürelerin içine difüzyonunun zorlaşmasından kaynaklanabileceği düşünülmüştür. Benzer sonuçlar literatürde verilmiştir [29].

\section{Sonuçlar}

TPP ile çapraz bağlanmış geleneksel olarak hazırlanan kitosan mikrokürelerinin ard arda KRG ve KTS ile kaplanması ile KTS kürelerinin düşük pH'lara olan dayanıklılığı artmıştır. Mikrokürelerin içinde hapsedilen IM'nin kimyasal kararlılığını koruduğu FTIR ve DSC ölçümleri ile kanıtlanmıştır. SEM çalışmaları ile mikrokürelerin küresel şekilli oldukları, KRG ile kaplandıktan sonra pürüzlü bir yüzeye sahip oldukları ve ilaç miktarının artması ile IM kristallerinin kürelerin yüzeyinde biriktikleri gözlemlenmiştir. Kontrollü salım testleri çapraz bağlayıcı TPP ve ilaç miktarının artması ile ilaç salımının azaldığını göstermiştir. Bu şekilde hazırlanacak KTS mikrokürelerin kontrollü ilaç salım sistemi olarak kullanılma olasılıklarının önemli ölçüde arttı̆̆ belirlenmiştir.

\section{Teşekkür}

Bu çalışma Kırıkkale Üniversitesi Bilimsel Araştırma Projeleri Koordinasyon Birimi tarafından 2013/45 proje numarası ile desteklenmiştir.

\section{Kaynaklar}

[1] Gürsoy AZ. Kontrollü Salım Sistemleri. İstanbul, Türkiye: Kontrollü Salım Sistemleri Derneği, 2002.

[2] Roberts GAF. Structure of chitin and chitosan. In: Roberts GAF, editors, Chitin Chemistry. London: MacMillan, 1992. pp. 1-53.

[3] Rha CK, Rodriguez-Sanchez D, Kienzle-Sterzer C. Novel applications of chitosan. In: Colwell RR, Pariser ER, Sinskey AJ, editors. Biotechnology of Marine Polysaccharides. Washington: Hemisphere, 1984. pp. 284-311.

[4] Struszczyk H, Wawro D, Niekraszewicz A. Biodegradability of chitosan fibres. In: Brine CJ, Sandford PA, Zikakis JP, editors. Advances in Chitin and Chitosan. Londra, İngiltere: Elsevier Applied Science, 1991. pp. 580-585

[5] Roberts GAF. Solubility and solution behaviour of chitin and chitosan. In: Roberts GAF, editors. Chitin Chemistry. Londra, İngiltere: MacMillan, 1992. pp. 274-329.

[6] Domard A, Cartier N. Glucosamine oligomers: 4.solid state-crystallization and sustained dissolution. Int J Biol Macromol 1992; 14: 100-106.

[7] Sannan T, Kurita K, Iwakura Y. Studies on chitin, 2. Effect of deacetylation on solubility. Macromol Chem Phys 1976; 177: 3589-3600. 
[8] Domínguez-Delgado CL, Rodríguez-Cruz IM, Fuentes-Prado E, Escobar-Chávez JJ, Vidal- Romero G, GarcíaGonzález L, Puente-Lee RI. Drug Carrier Systems Using Chitosan for Non Parenteral Routes. In: Gowder SJT, editor. Pharmacology and Therapeutics. Londra, İngiltere: Intech Open Limited, 2014. pp. 273-325

[9] Berscht PC, Nies B, Liebendorfer A, Kreuter J. Incorporation of basic fibroblast growth factor into methylpyrrolidinone chitosan fleeces and determination of the in vitro release characteristics. Biomaterials 1994; 15: $593-600$.

[10] Ilium L. Chitosan and Its Use as a Pharmaceutical Excipient. Pharm Res 1998; 15: 1326- 1331.

[11] Dodane V, Vilivalam VD, Pharmaceutical applications of chitosan. Pharm Sci Technol Today 1998; 1, $246-253$.

[12] Coviello T, Matricardi P, Marianecci C, Alhaique F. Polysaccharide hydrogels for modified release formulations. J Cont Rel 2007; 119: 5-24.

[13] Jiao G, Yu G, Zhang J, Ewart HS. Chemical structures and bioactivities of sulfated polysaccharides from marine algae. Mar Drugs 2011; 9: 196-223.

[14] Campo VL, Kawano DF, Silva DB, Carvalho DI. Carrageenans: Biological properties, chemical modifications and structural analysis-A review. Carbohyd Polym 2009; 77: 167-180.

[15] Nanaki S, Karavas E, Kalantzi L, Bikiaris D. Miscibility study of carrageenan blends and evaluation of their effectiveness as sustained release carriers. Carbohyd Polym 2010; 79: 1157-1167.

[16] Necas J, Bartosikova L. Carrageenan: A review. Vet Med Czech 2013; 58: 187-205.

[17] Tapiaa C, Escobar Z, Costa E, Sapag-Hagar J, Valenzuela F, Basualto C, Gai MN, Yazdani-Pedram M. Comparative studies on polyelectrolyte complexes and mixtures of chitosan-alginate and chitosan-carrageenan as prolonged diltiazem clorhydrate release systems. Eur J Pharm Biopharm 2004; 57: 65-75.

[18]Long J, Yu X, Xu E, Wu Z, Xu X, Jin Z, Jiao A. In situ synthesis of new magnetite chitosan/carrageenan nanocomposites by electrostatic interactions for protein delivery applications. Carbohyd Polym 2015; 131: 98-107.

[19] Eis MJ, Watkins BM, Philip A, Welling RE. Nonsteroidal-induced benign strictures of the colon: a case report and review of the literature. Am J Gastroenterol 1998; 93, 120-121.

[20] Bogdanova S, Bontcheva E, Avramova N. Phase characterization of indomethacin in adsorbates onto hydroxyethylcellulose. Drug Dev Ind Pharm 2007; 33: 900-906.

[21] Jain AK. Solubilization of indomethacin using hydrotropes for aqueous injection. Eur J Pharm Biopharm 2008; 68: 701-714.

[22] Piyakulawat P, Praphairaksit N, Chantarasiri N, Muangsin N. Preparation and evaluation of chitosan/carrageenan beads for controlled release of sodium diclofenac. AAPS Pharm Sci Tech 2007; 8(4), E1-E11.

[23] Salgueiro AM, Daniel-da-Silva AL, Girão AV, Pinheiro PC, Trindade T. Unusual dye adsorption behavior of $\kappa$ carrageenan coated superparamagnetic nanoparticles. Chem Eng J 2013; 229, $276-284$.

[24] Angadi SC, Manjeshwar LS, Aminabhavi TM. Stearic acid-coated chitosan-based interpenetrating polymer network microspheres: controlled release characteristics. Ind Eng Chem Res 2011; 50, 4504-4514.

[25] O’Brien M, McCauley J, Cohen E. Indomethacin. In: Florey K, editor, In Analytical Profiles of Drug Substances. New York: Academic Press, 1984. pp. 211-238.

[26] Işıklan N, İnal M, Kurşun F, Ercan G. pH responsive itaconic acid grafted alginate microspheres for the controlled release of nifedipine. Carbohyd Polym 2011; 84: 933-943.

[27] Debrassi A, Bürger C, Rodrigues CA, Nedelko N, Waniewska AS, Dłuzewski P, Sobczak K, Greneche JM. Synthesis, characterization and in vitro drug release of magnetic N-benzyl-O-carboxymethylchitosan nanoparticles loaded with indomethacin. Acta Biomater 2011; 7, 3078-3085.

[28] Qu X, Wirsen A, Albertsson AC. Novel pH-sensitive chitosan hydrogels: swelling behavior and states of water. Polymer 2000; 41: 4589-4598.

[29] Iman M, Maji TK. Effect of crosslinker and nanoclay on starch and jute fabric based green nanocomposites. Carbohyd Polym 2012; 89, 290-297. 